\title{
Design of Two Wheeler Electric Vehicle Ignitia V1.0
}

Manoj Pal ${ }^{1 *}$, Md Ahtezaz Parways ${ }^{2}$, Mohd Aqif ${ }^{2}$ and Shahid Hussain ${ }^{2}$

${ }^{1}$ Department of Mechanical Engineering, SRM University NCR, New Delhi, India

${ }^{2}$ Mechanical Engineering, SRM University NCR, New Delhi, India

\begin{abstract}
This study includes the virtual design of two wheeler electrical vehicle on CATIA V5 with consideration of advance comfort, trendy look, light weight and good mileage comparison with existing model. The study also includes the maximum weight loading analysis of the chassis material of EV IGNITIA V1.0 on Autodesk Inventor 2013 static force analysis
\end{abstract}

Keywords: CATIA V5 virtual design; Stress analysis; Ergonomics

\section{Introduction}

A IGNITIA V1.0 is a two wheeler electric vehicle having four basic unit and i.e. transmission system, suspensions, breaking and chassis.

\section{Technical specification}

Transmission: Hub derive

Motor type: Brushless 750W/48V

Dimensions: $1885 \times 655 \times 1040 \mathrm{~mm}$, Wheelbase $1265 \mathrm{~mm}$

Weight: $96 \mathrm{~kg}$

Controller: Programmable CPU Top speed: $40 \mathrm{~km} / \mathrm{hr}$

Battery: Lithium Ion 4 pack $(4 \times 12) 48 \mathrm{~V}$ Wheel: Aluminum

Braking system: Disk Brake

Suspensions: Hydraulic Dampers front and rear both

Tires: Nylon, 16 inch diameter front and rear

\section{Design specification of ignition V 1.0}

Note: We design this vehicle virtually so all the technical specification is theoretical.

The designing procedure has been completed on CATIA V5 with all standards of market and customized properties [1] of the vehicle (Figures 1 and 2).

\section{Frame Analysis}

The frame is made up of "Mild Steel Grade S 303." The structure

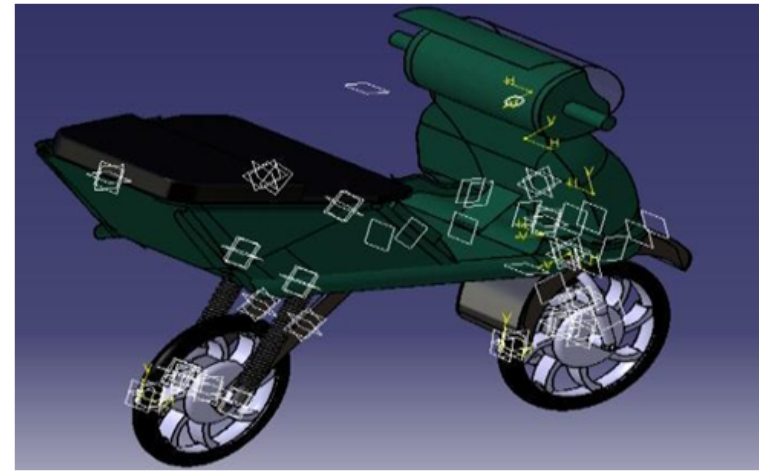

Figure 1: CATIA V5 design image of the two wheeler EV IGNITIA V1.0, side view [4]. is normal struts type with uniform body structure. The joints are considered as welded with MIG welding process (Figure 3). The static load analysis is done on Autodesk Inventor Professional 2013 CAD Package [2,3] with boundary conditions only (Tables 1 and 2). The

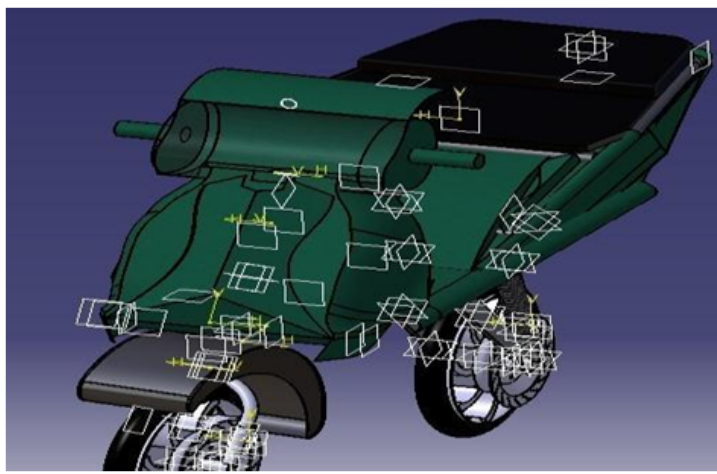

Figure 2: Catia Design Image of the two wheeler EV IGNITIA V1.0, front view.

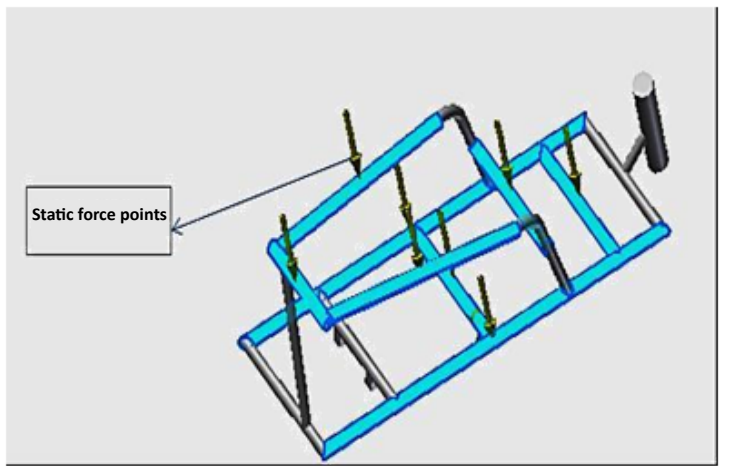

Figure 3: Frame with Static Force Points and constraint.

*Corresponding author: Manoj Pal, Assistant Professor, Department of Mechanical Engineering, SRM University NCR, New Delhi, India, Tel: +91-1232234301; E-mail: manojsantosh2002@gmail.com

Received February 11, 2014; Accepted May 01, 2014; Published May 09, 2014

Citation: Pal M, Parways MA, Aqif M, Hussain S (2014) Design of Two Wheeler Electric Vehicle Ignitia V1.0. J Appl Mech Eng 3: 142. doi:10.4172/21689873.1000142

Copyright: (c) 2014 Pal M, et al. This is an open-access article distributed under the terms of the Creative Commons Attribution License, which permits unrestricted use, distribution, and reproduction in any medium, provided the original author and source are credited. 
Citation: Pal M, Parways MA, Aqif M, Hussain S (2014) Design of Two Wheeler Electric Vehicle Ignitia V1.0. J Appl Mech Eng 3: 142. doi:10.4172/21689873.1000142

Page 2 of 3

\begin{tabular}{|l|l|}
\hline Material & Steel, Mild \\
\hline Density & $7.86 \mathrm{~g} / \mathrm{cm}^{\mathrm{A}} 3$ \\
\hline Mass & $45.1746 \mathrm{~kg}$ \\
\hline Area & $718887 \mathrm{~mm}^{\mathrm{A}} 2$ \\
\hline Volume & $5747400 \mathrm{~mm}^{\mathrm{A}} 3$ \\
\hline Center of Gravity & $\mathrm{x}=94.5993 \mathrm{~mm} \quad \mathrm{y}=-37.9994 \mathrm{~mm} \mathrm{z}=0.494178 \mathrm{~mm}$ \\
\hline
\end{tabular}

Table 1: Frame Material Specification.

\begin{tabular}{|l|l|}
\hline Design Objective & Single Point \\
\hline Simulation Type & Static Analysis \\
\hline Constraints & Fixed Type \\
\hline Detect and Elimiate Rigid Body Modes & No \\
\hline
\end{tabular}

Table 2: Operation specification input data.

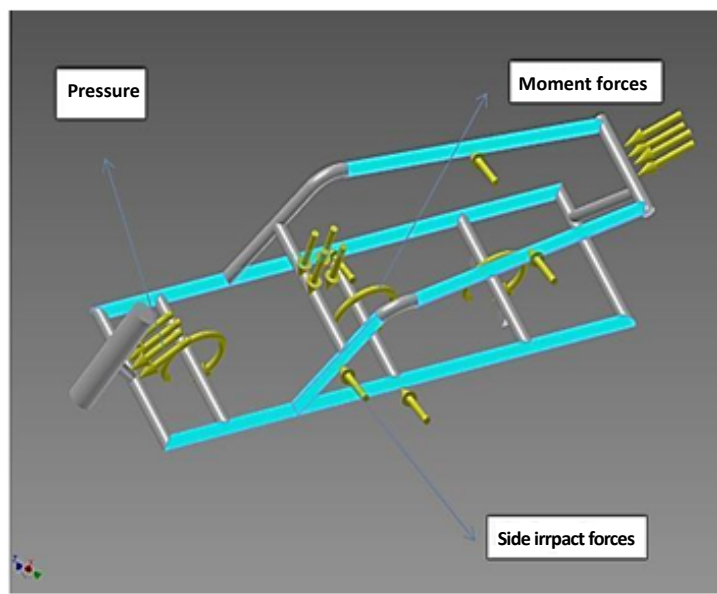

Figure 4: Frame with Pressure, Moment Forces and Side Impact Forces Points.

\begin{tabular}{|l|l|}
\hline Avg. Element Size (fraction of model diameter) & 0.1 \\
\hline Min. Element Size (fraction of avg. size) & 0.2 \\
\hline Grading Factor & 1.5 \\
\hline Max. Turn Angle & $60 \mathrm{deg}$ \\
\hline Create Curved Mesh Elements & Yes \\
\hline
\end{tabular}

Table 3: Mesh element details [2,3].

testing completed on software was for minimum and maximum values of various loads and stress (Figure 4).

\section{Considerations}

The constraint included in this is fixed type constraint with max. Degree of Freedom is 3 and min. is zero. The load has been considered static on the vehicle with maximum loading condition. It includes the total weight of the vehicle including driver, co-driver, luggage and selfbody weight. The initial torque is also considered as rotational moment on fixed constraints [4] of chassis and wheel.

\section{Meshing}

Tetrahedralmesh [5] is considered for the analysis of frame. Average element size (fraction of model diameter) is 0.1 , minimum element size (fraction of average element size) is 0.2 , grading factor is 1.5 , and max. Turn angle is 60 degree (Tables 3 and 4 ). Total numbers of nodes are 21323 and elements are 11652 as shown in (Figures 5-7). This stage of part design gives accuracy of more than $99.5 \%$ regarding efficiency of it. These meshes are generated accordingly to the forces, loads and moments applied (Table 5). These are the nodal points which

\begin{tabular}{|c|c|c|}
\hline \multirow{2}{*}{ Name } & \multicolumn{2}{|c|}{ Steel, Mild } \\
\hline \multirow{3}{*}{ General } & Mass Density & $7.86 \mathrm{~g} / \mathrm{cm}^{\mathrm{A}} 3$ \\
\cline { 2 - 3 } & Yield Strength & $207 \mathrm{MPa}$ \\
\cline { 2 - 3 } & Ultimate Tensile Strength & $345 \mathrm{MPa}$ \\
\hline \multirow{2}{*}{ Stress } & Young's Modulus & $220 \mathrm{GPa}$ \\
\cline { 2 - 3 } & Poisson's Ratio & $0.275 \mathrm{ul}$ \\
\hline \multirow{2}{*}{ Stress } & Shear Modulus & $86.2745 \mathrm{GPa}$ \\
\cline { 2 - 3 } Thermal & Expansion Coefficient & $0.000012 \mathrm{ul} / \mathrm{c}$ \\
\cline { 2 - 3 } & Thermal Conductivity & $56 \mathrm{~W} /(\mathrm{m} \mathrm{K})$ \\
\hline Part Name(s) & Specific Heat & $460 \mathrm{~J} /(\mathrm{kg} \mathrm{c})$ \\
\hline
\end{tabular}

Table 4: Material specifications [5].

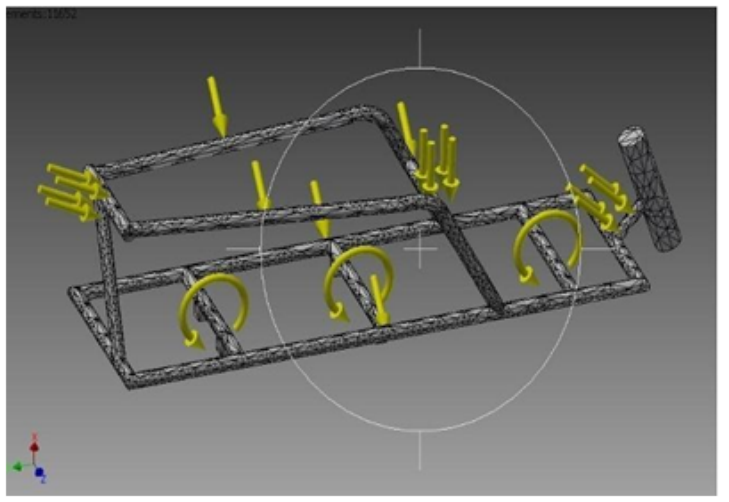

Figure 5: Tetrahedral Mesh frame.

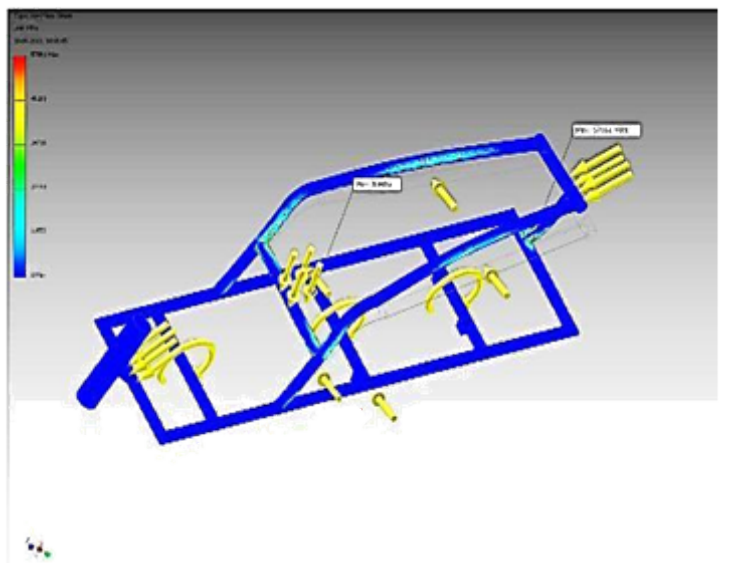

Figure 6: Von Miss Stress results

give exact figure of stress analysis, factor of safety and fatigue analysis of the materials.

\section{Simulation Data}

After running the program the following value tables are generated from the Autodesk inventor software which exactly gives us the value of maximum load and minimum load criteria for our design and ideal vehicle specification (Table 6).

\section{Results}

According to the interpretation of the table values color histograms 
Citation: Pal M, Parways MA, Aqif M, Hussain S (2014) Design of Two Wheeler Electric Vehicle Ignitia V1.0. J Appl Mech Eng 3: 142. doi:10.4172/21689873.1000142

Page 3 of 3

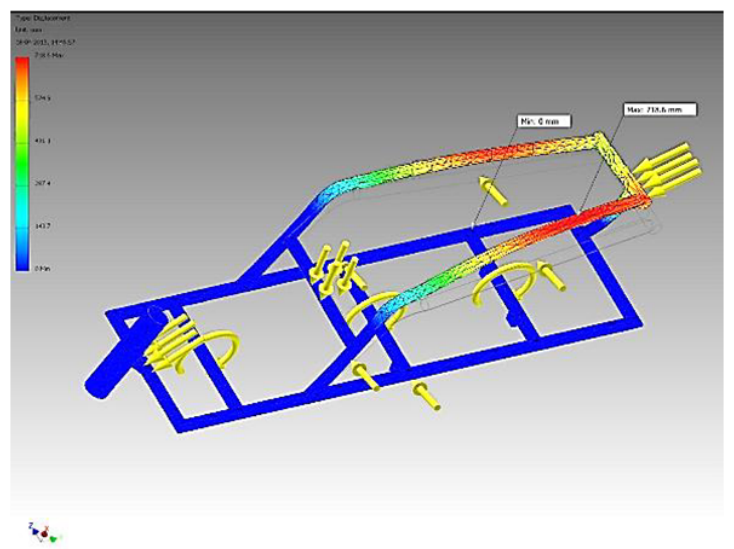

Figure 7: Maximum Displacements Results.

\begin{tabular}{|c|c|}
\hline Load Type & Force \\
\hline Magnitude & $5004770.0320 \mathrm{~N}$ \\
\hline Vector $X$ & $-2028050.391 \mathrm{~N}$ \\
\hline Vector $Y$ & $533606.915 \mathrm{~N}$ \\
\hline Vector $Z$ & $4538972.931 \mathrm{~N}$ \\
\hline
\end{tabular}

Table 5: Operation condition, data of force applied [2].

\begin{tabular}{|c|c|c|c|c|}
\hline \multirow[b]{2}{*}{ Constraint Name } & \multicolumn{2}{|c|}{ Reaction Force } & \multicolumn{2}{|c|}{ Reaction Moment } \\
\hline & Magnitude & $\begin{array}{c}\text { Component } \\
(X, Y, Z)\end{array}$ & Magnitude & $\begin{array}{c}\text { Component } \\
(X, Y, Z)\end{array}$ \\
\hline \multirow{3}{*}{ Fixed Constarint: 1} & \multirow{3}{*}{$5149410 \mathrm{~N}$} & $2425230 \mathrm{~N}$ & \multirow{3}{*}{$\begin{array}{c}553081 \\
\mathrm{~N} \mathrm{~m}\end{array}$} & $-327348 \mathrm{~N} \mathrm{~m}$ \\
\hline & & $232254 \mathrm{~N}$ & & $427017 \mathrm{~N} \mathrm{~m}$ \\
\hline & & $-4536600 \mathrm{~N}$ & & $-128056 \mathrm{~N} \mathrm{~m}$ \\
\hline \multirow{3}{*}{ Fixed Constraints } & \multirow{3}{*}{$1.89081 \mathrm{~N}$} & $1.8615 \mathrm{~N}$ & \multirow{3}{*}{$\begin{array}{l}0.224292 \\
\mathrm{~N} \mathrm{~m}\end{array}$} & $0.0945 \mathrm{~N} \mathrm{~m}$ \\
\hline & & $-240465 N$ & & $-0.042 \mathrm{~N} \mathrm{~m}$ \\
\hline & & $0.228388 \mathrm{~N}$ & & $-0.198 \mathrm{~N} \mathrm{~m}$ \\
\hline
\end{tabular}

Table 6: Reaction Force and Moment on Constraint [4,5]

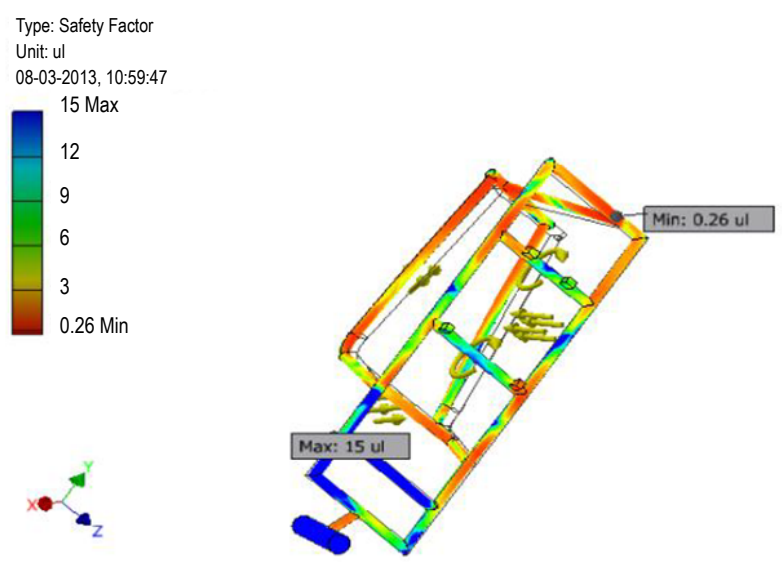

Figure 8: Safety Factor results.

has been generated. The value of histogram varied from max. to min. with their color contrast (Table 7). According to the values factor of safety obtained is 3 and max as shown in Figure 8 .

\section{Conclusions}

The interpretation of the results is positive for the desire criteria.

\begin{tabular}{|c|c|c|}
\hline Name & Minimum & Maximum \\
\hline Volume & \multicolumn{2}{|c|}{$5737800 \mathrm{~mm}^{\mathrm{A}} 3$} \\
\hline Mass & \multicolumn{2}{|c|}{$45.0991 \mathrm{~kg}$} \\
\hline Von Mises Stress & $0.000000000565748 \mathrm{MPa}$ & $57860.8 \mathrm{MPa}$ \\
\hline $1^{\text {st }}$ Principal Stress & $-9292.06 \mathrm{MPa}$ & $63994.3 \mathrm{MPa}$ \\
\hline $3^{\text {rd }}$ Principal Stress & $-44605.1 \mathrm{MPa}$ & $15330.1 \mathrm{MPa}$ \\
\hline Displacement & $0 \mathrm{~mm}$ & $12.455 \mathrm{~mm}$ \\
\hline Safety Factor & $0.00357755 \mathrm{ul}$ & $15 \mathrm{ul}$ \\
\hline Stress XX & $-43676.4 \mathrm{MPa}$ & 57996.3 MPa \\
\hline Stress $\mathbf{X Y}$ & $-15319.3 \mathrm{MPa}$ & $18173.9 \mathrm{MPa}$ \\
\hline Stress XZ & $-17665.8 \mathrm{MPa}$ & $22247.2 \mathrm{MPa}$ \\
\hline Stress YY & $-20745 \mathrm{MPa}$ & $24785.7 \mathrm{MPa}$ \\
\hline Stress YZ & $-6356.96 \mathrm{MPa}$ & 10868.7 MPa \\
\hline Stress ZZ & $-33439 \mathrm{MPa}$ & 32974.4 MPa \\
\hline X Displacement & $-228.29 \mathrm{~mm}$ & $428.397 \mathrm{~mm}$ \\
\hline Y Displacement & $-143.982 \mathrm{~mm}$ & $54.5902 \mathrm{~mm}$ \\
\hline Z Displacement & $-3.19758 \mathrm{~mm}$ & $673.259 \mathrm{~mm}$ \\
\hline Equivalent Strain & 0.00000000000000257516 ul & $0.235432 \mu \mathrm{l}$ \\
\hline $1^{\text {st }}$ Principal Strain & $-0.000482355 \mu \mathrm{l}$ & $0.275154 \mu \mathrm{l}$ \\
\hline $3^{\text {rd }}$ Principal Strain & $-0.200584 \mu \mathrm{l}$ & $0.0000000218705 \mu \mathrm{l}$ \\
\hline Strain XX & $-0.187881 \mu \mathrm{l}$ & $0.240393 \mu \mathrm{l}$ \\
\hline Strain $\mathbf{X Y}$ & $-0.0887824 \mu \mathrm{l}$ & $0.105326 \mu \mathrm{l}$ \\
\hline Strain XZ & $-0.102382 \mu \mathrm{l}$ & $0.128933 \mu \mathrm{l}$ \\
\hline Strain YY & $-0.092741 \mu \mathrm{l}$ & $0.0951339 \mu \mathrm{l}$ \\
\hline Strain YZ & $-0.0368415 \mu \mathrm{l}$ & $0.0629889 \mu \mathrm{l}$ \\
\hline Strain ZZ & $-0.14451 \mu \mathrm{l}$ & $0.143729 \mu \mathrm{l}$ \\
\hline
\end{tabular}

Table 7: Summarized simulation results [3-5].

According to the given load conditions the frame is safe. The frame is under maximum load and it's obtained the desire factor of safety. The simulation tables are having the desired range of deformation and displacement values. The frame is required no modifications further and safe enough for all kind of given loads.

\section{References}

1. Pratt MJ (1984) Solid Modeling and the Interface between Design and Manufacture, IEEE Computer Graphics and Applications 4: 52-59.

2. Rogers JL, Barthelemy JFM (1986) An Expert System for Choosing the Best Combinations of Options in a General PurposeProgramforAutomatedDesign Synthesis. Engineering with Computer 1: 217-227.

3. http://www.autodesk.com/education/free-software/all

4. Nader G, Weaver JM (2012) CATIA V5 Tutorial. SDC Publication.

5. Rinderle JR (1987) Function and Form Relationships: A Basis for Preliminary Design. Carnegie Mellon University, Pittsberg, USA. 